\title{
Avaliação do uso de elicitores de resistência bióticos e abióticos contra a antracnose na videira (Vitis labrusca L.)
}

\author{
Hilderlande Florêncio da Silva ${ }^{1}$; Kedma Maria Silva Pinto ${ }^{2}$; Luciana Cordeiro do Nascimento ${ }^{1}$; Edcarlos Camilo da \\ Silva'; Wilza Carla Oliveira de Souza ${ }^{3}$
}

${ }^{1}$ Programa de Pós-Graduação em Agronomia, Universidade Federal da Paraíba, Campus II, Areia, PB, Brasil, CEP: 58.397-000. ${ }^{2}$ Universidade Rural de Pernambuco, Unidade Acadêmica de Garanhuns, Garanhuns, PE, Brasil, CEP: 55.292-270. ${ }^{3}$ Instituto Federal de Educação, Ciência e Tecnologia do Sertão Pernambucano, Campus Floresta, Floresta, PE, Brasil. CEP: 56.400-000.

Autor para correspondência: Hilderlande Florêncio da Silva (hildafs@hotmail.com).

Data de chegada: 25/05/2017. Aceito para publicação em: 27/03/2018.

$10.1590 / 0100-5405 / 180414$

\section{RESUMO}

Silva, H.F.; Pinto, K.M.S.; Nascimento, L.C.; Silva, E.C.; Souza, W.C.O. Avaliação do uso de elicitores de resistência bióticos e abióticos contra a antracnose na videira (Vitis labrusca L.). Summa Phytopathologica, v.45, n.1, p.70-75, 2019.

A antracnose da videira é uma doença causada pelo fungo Elsinoe ampelina sendo responsável por grandes danos na cultura. A proteção de plantas por meio da resistência induzida tem sido visualizada como uma importante medida de controle alternativo. Os elicitores de resistência estimulam uma série de reações no hospedeiro, para a produção de compostos metabólicos propiciando proteger a planta contra os patógenos. O objetivo do trabalho foi avaliar a eficiência de elicitores de resistência bióticos e abióticos no manejo da antracnose na cultura da videira 'Isabel'. O experimento a campo foi realizado no município de Natuba, PB e as análises de fruto no Laboratório de Fitopatologia da Universidade Federal da Paraíba, em Areia. Os tratamentos utilizados foram: T1 - Testemunha; T2 Fungicida (Metiram + Piraclostrobina); T3 - Fosfito de Potássio; T4 - AgroMos $^{\circledR}$; T5 - Fungicida + Fosfito de Potássio; T6 - Fungicida + AgroMos ${ }^{\circledR} ;$ T7 - Fosfito de Potássio + AgroMos ${ }^{\circledR} ;$ T8 - Fungicida + Fosfito de Potássio + AgroMos $^{\circledR}$ com quarto repetições em blocos casualizado. As aplicações foram realizadas a cada sete dias, totalizando 12 aplicações durante o ciclo da cultura. As avaliações foram realizadas quinzenalmente, avaliando-se nove folhas por planta. As variáveis analisadas foram: período de incubação, incidência da doença e área abaixo da curva de progresso da doença. Para avaliações físico-químicas dos frutos, o delineamento foi em blocos ao acaso, constituída de três cachos. Foram analisados: peso dos cachos; comprimento e diâmetro dos cachos; rendimento de polpa; sólidos solúveis; $\mathrm{pH}$; acidez titulável e relação SS/AT. O fosfito de potássio aplicado sozinho ou intercalado com fungicida e/ou AgroMos ${ }^{\circledR}$ em videiras 'Isabel', proporcionou menor severidade de E. ampelina. O comprimento e peso dos cachos de uva foram influenciados positivamente com a aplicação de fosfito de potássio. O Fosfito de potássio e AgroMos ${ }^{\circledR}$ aplicados isoladamente ou em conjunto, não interferiram no rendimento de polpa.

Palavras-chave: Controle; Elsinoe ampelina; incidência; pós-colheita

\section{ABSTRACT}

Silva, H.F.; Pinto, K.M.S.; Nascimento, L.C.; Silva, E.C.; Souza, W.C.O. Evaluation of the use of biotic and abiotic resistance elicitors against anthracnose in grapevine (Vitis labrusca L.). Summa Phytopathologica, v.45, n.1, p.70-75, 2019.

Anthracnose of grapevine is a disease caused by the fungus Elsinoe ampelina, responsible for great damages to the crop. Plant protection by means of resistance induction has been viewed as an important alternative control measure. Resistance elicitors stimulate a series of reactions in the host for the production of metabolic compounds, providing protection to the plant against pathogens. The aim of this study was to evaluate the efficiency of biotic and abiotic resistance elicitors in the management of anthracnose for the cultivation of vine 'Isabel'. The experiment in the field was carried out in the municipality of Natuba, Paraíba State, and fruits were analyzed in the Phytopathology Laboratory of Federal University of Paraiba, Areia. Treatments were: T1 - Control; T2 - Fungicide (Metiram + Pyraclostrobin); T3 - Potassium phosphite; T4 - AgroMos ${ }^{\circledR}$; T5 - Fungicide + Potassium phosphite; T6 - Fungicide + AgroMos $^{\circledR}$, T7 - Potassium phosphite +
AgroMos $^{\circledR} ;$ T8 - Fungicide + Potassium phosphite + AgroMos ${ }^{\circledR}$ composed of four replicates in randomized blocks. Applications were carried out at every seven days, totaling 12 applications during the crop cycle. Evaluations were done at every 15 days, considering nine leaves per plant. The analyzed variables were: incubation period, disease incidence and area below the disease progress curve. For physicochemical evaluations of fruits, the design was in randomized blocks, constituted of three clusters. The following were analyzed: bunch weight; bunch length and diameter; pulp yield; soluble solids; $\mathrm{pH}$; titratable acidity and SS / TA ratio. Potassium phosphite applied alone or alternated with fungicide and/or AgroMos ${ }^{\circledR}$ on vines «Isabel〉 provided lower severity of E. ampelina. The length and the weight of grape bunches were positively influenced by potassium phosphite application. Potassium phosphite and AgroMos ${ }^{\circledR}$ applied either alone or in association did not affect pulp yield.

Keywords: Control; Elsinoe ampelina; incidence; postharvest

A vitivinicultura apresenta-se com uma atividade economicamente importante no agronegócio brasileiro (15). No cenário nacional, a produção de uvas em 2015 atingiu cerca de 1,49 milhões de toneladas (11). No estado da Paraíba, o município de Natuba localizado na mesorregião do Agreste Paraibano destaca-se como único produtor de uva, com uma produção de 2.160 toneladas em 2015, e predomínio do cultivar 'Isabel', sendo a viticultura, juntamente com o cultivo da banana (Musa spp.) as principais fontes de renda do município (11). 
Um dos principais problemas para os viticultores de todas as regiões de produção de uva no Brasil são as doenças fúngicas. A antracnose da videira é uma doença causada pelo fungo Elsinoe ampelina (de Bary) Shear (Sphaceloma ampelinum de Bary), em anos de condições favoráveis, o ataque do fitopatógeno pode ser tão severo que os prejuízos chegam a comprometer não apenas a produtividade anual como também produtividades futuras (23).

O manejo desta doença é uma das necessidades primordiais, sabendo-se que é praticado o uso excessivo de produtos químicos. Devido a esta circunstância, os indutores de resistência aparecem como uma alternativa propícia para o controle de doenças na cultura (9). O uso de elicitores de resistência entre outras técnicas alternativas são opções ecológicas que propícia a substituição da proteção tradicional proporcionada pela aplicação de fungicidas, podendo ser utilizada juntamente com outras práticas de manejo integrado de doenças (5).

Sendo assim o objetivo do trabalho foi avaliar a eficiência de elicitores de resistência bióticos e abióticos como componente do manejo da antracnose na cultura da videira 'Isabel'.

\section{MATERIAL E MÉTODOS}

$\mathrm{O}$ experimento foi realizado em área comercial de produção de videira da cultivar 'Isabel', plantadas com espaçamentos de 1,5 x 1,5 m, com uma área de $2.500 \mathrm{~m}^{2}$, localizada no município de Natuba-PB, no Sítio Fervedouro (35 32' W e 07 35' S), no período de fevereiro a junho de 2010. As análises de qualidade físico-químicas foram realizadas no Laboratório de Fitopatologia do Centro de Ciências Agrárias da Universidade Federal da Paraíba, Areia-PB.

As pulverizações com elicitores foram realizadas em intervalos de sete dias, iniciando-se 20 dias após a poda das videiras, utilizando pulverizador costal manual com capacidade de $20 \mathrm{~L}$, perfazendo um total de 12 aplicações, num período de três meses.

O delineamento experimental foi em blocos ao acaso, constituído de oito tratamentos: T1 - Testemunha (Sem aplicação); T2 - Fungicida ((Metiram + Piraclostrobina) $2 \mathrm{~kg} / \mathrm{ha}$; T3 - Fosfito de Potássio $130 \mathrm{~g} / 100$ L; T4 - $\operatorname{AgroMos}^{\circledR}$ (Mananoligossacarideo Fosforilado) 3mL/L; T5 Fungicida ((Metiram + Piraclostrobina) + Fosfito de Potássio (1 kg/ha) / (65 g/100 L); T6 - Fungicida ((Metiram + Piraclostrobina) + AgroMos $^{\circledR}$ (Mananoligossacarideo Fosforilado) (1 kg/ha) / (1,5 mL/L); T7 - Fosfito de Potássio + AgroMos ${ }^{\circledR}$ (Mananoligossacarideo Fosforilado) (65 $\mathrm{g} / 100 \mathrm{~L}) /(1,5 \mathrm{~mL} / \mathrm{L}) ; \mathrm{T} 8$ - Fungicida ((Metiram + Piraclostrobina) + Fosfito de Potássio + AgroMos $^{\circledR}$ (Mananoligossacarideo Fosforilado) $(0,65 \mathrm{~kg} / \mathrm{ha}) /(43 \mathrm{~g} / 100 \mathrm{~L}) /(1 \mathrm{~mL} / \mathrm{L})$, e quatro repetições, sendo a unidade experimental composta por 5 plantas. Os tratamentos com mais de um produto foram aplicados de forma intercalada (T5; T6; T7 e T8), segundo metodologia adaptada de Gomes et al. (9). As avaliações foram realizadas quinzenalmente totalizando oito avaliações utilizando-se o método de amostragem definido pela Produção Integrada de Frutas PIF da uva; nove folhas por planta (três folhas do ramo basal, três do ramo mediano e três do ramo apical).

As variáveis analisadas foram o período de incubação (dias), referente ao primeiro dia do surgimento dos sintomas típicos do patógeno; incidência da doença (\%), correspondente a porcentagem total de folhas com sintomas em relação ao número total de folhas avaliadas e área abaixo da curva de progresso da doença - AACPD, construída com os índices de incidência obtidos nas avaliações. As médias foram comparadas pelo Teste de Tukey até $5 \%$ de probabilidade, utilizando-se o software estatístico ASSISTAT $^{\circledR}$ versão 7.5 beta (20).
As coletas dos frutos de videira foram realizadas aos 120 dias após a poda, para avaliar a interferência dos elicitores na qualidade póscolheita. Destes, foram retirados três cachos por repetição, totalizando 12 frutos por tratamento, aos quais foram conduzidos ao Laboratório de Fitopatologia (LAFIT), onde foram realizadas as avaliações físicas de peso dos frutos em gramas (PF g), comprimento do cacho (CC) e diâmetro do cacho (DC), mensurados com paquímetro digital $(\mathrm{cm})$ e rendimento de polpa em gramas (REND g).

Nas análises químicas avaliou-se o teor de sólidos solúveis totais, expresso em ${ }^{\circ} \mathrm{Brix}(12)$, o pH em $\mathrm{pHmetro}$ digital, a acidez total titulável definido pela titulação com $\mathrm{NaOH}$ 0,1 $\mathrm{N}$ com resultados expressos em percentagem (1). A relação sólidos solúveis/acidez titulável foi realizada como parâmetro para estabelecer a maturação ideal das uvas destinadas ao consumo in natura.

Os dados obtidos foram submetidos a análise de variância e se significativas as médias dos tratamentos comparadas pelo Teste de Tukey até $5 \%$ de probabilidade, por meio do software estatístico $\operatorname{ASSISTAT}^{\circledR}$ versão 7.5 beta (20).

\section{RESULTADOS E DISCUSSÕES}

Para a variável Período de Incubação (PI), alguns tratamentos anteciparam o início da infecção em até 14 dias como o AgroMos ${ }^{\circledR}$ e o Fosfito de Potássio + AgroMos $^{\circledR}$, porém não diferindo estatisticamente dos tratamentos Fungicida + AgroMos $^{\circledR}$ e Fungicida + Fosfito de potássio $+\operatorname{AgroMos}^{\circledR}$ (Tabela 1).

Resultados semelhantes foram observados por Pinto et al., (17), ao constatarem que os mesmos elicitores e combinações, não foram capazes de retardar o avanço dos sintomas nas plantas de videiras tratadas para o controle do míldio (Plasmopora viticola), em que os primeiros sintomas da doença foram observados com 21 dias após a poda.

De acordo com os dados obtidos na Tabela 1, constatou-se que o uso de AgroMos ${ }^{\circledR}$, em qualquer dose, mesmo combinado com os demais tratamentos não foi eficiente sobre a infecção do patógeno, antecipando o surgimento dos sintomas, quando comparado a testemunha, e os tratamentos fosfito de potássio e fungicida + fosfito de potássio.

Gomes et al., (9) evidenciaram a eficiência do fosfito de potássio em plantas de videira 'Isabel', cultivadas no município de Natuba-PB, durante a safra de julho a dezembro de 2008, no qual, plantas tratadas com AgroMos ${ }^{\circledR}$ e fosfito de potássio não diferiram estatisticamente das tratadas com fungicida registrado Cabriotop ${ }^{\circledR}$ (Metiram + Piraclostrobina) para a cultura, sendo eficiente no controle do míldio da videira.

Através da análise dos dados de incidência da antracnose, para cultivar 'Isabel', constatou-se que apenas o tratamento AgroMos ${ }^{\circledR}$ não foi eficiente na redução do patógeno, não diferindo estatisticamente da testemunha (Tabela 1). Os demais tratamentos reduziram a incidência da doença entre 60,8\% para o tratamento Fosfito de Potássio + AgroMos ${ }^{\circledR}$ e $90,54 \%$ para o tratamento Fungicida.

A aplicação do fosfito é indicada para todos os tipos de cultivo sendo favorável na defesa e na redução dos sintomas produzidos pelos patógenos, entretanto, sua utilização está relacionada principalmente com a melhoria do estado nutricional das plantas, além de tudo nas fases de elevado aumento nas atividades metabólicas, favorecendo a maturação e a qualidade dos frutos, garantindo sobre tudo que a qualidade pós-colheita seja superior (16).

$\mathrm{O}$ fosfito tem o poder de atuar sobre a doença diretamente 
Tabela 1. Período de Incubação (PI) e Incidência (I) da antracnose em videira 'Isabel' submetidas a diferentes tratamentos com fungicidas e elicitores de resistência, em condições de campo no município de Natuba, PB.

\begin{tabular}{|c|c|c|}
\hline Tratamentos & PI & I \\
\hline Testemunha & $79,0 \mathrm{a}^{1}$ & $41,11 a^{1}$ \\
\hline Fungicida & $75,5 \mathrm{ab}$ & $3,89 \mathrm{~b}$ \\
\hline Fosfito de Potássio & $79,0 \mathrm{a}$ & $4,47 b$ \\
\hline $\operatorname{AgroMos}^{\circledR}$ & $65,0 \mathrm{c}$ & $53,33 \mathrm{a}$ \\
\hline Fungicida + Fosfito de Potássio & $79,0 \mathrm{a}$ & $4,44 \mathrm{~b}$ \\
\hline Fungicida + AgroMos ${ }^{\circledR}$ & $68,5 \mathrm{bc}$ & $7,22 \mathrm{~b}$ \\
\hline Fosfito de Potássio + AgroMos $^{\circledR}$ & $65,0 \mathrm{c}$ & $16,11 \mathrm{~b}$ \\
\hline Fungicida + Fosfito de Potássio + AgroMos ${ }^{\circledR}$ & $68,5 \mathrm{bc}$ & $5,55 \mathrm{~b}$ \\
\hline CV $(\%)$ & 5,92 & 44,32 \\
\hline
\end{tabular}

${ }^{1}$ Médias seguidas da mesma letra não diferem estatisticamente entre si pelo teste de Tukey até $5 \%$ de probabilidade.

ou indiretamente, sendo diretamente quando o fosfito dificulta o desenvolvimento dos patógenos e indiretamente no momento em que impulsiona na planta a produção de substância (enzimas, fenóis e fitoalexinas) que desempenha defesa contra o patógeno (3).

Silva et al. (21), comprovaram que plantas de soja (Glycine max) tratadas com fosfito de potássio apresentaram um maior índice de área foliar, entretanto este efeito pode estar associado com ao controle do míldio da soja (Peronospora manshurica), sendo observados pelos autores um possível efeito nutricional desse elicitor.

Em resultados obtidos por Dianese et al. (7) foi verificado que a utilização de fosfito de potássio em mudas de mamoeiro (Carica papaya) proporcionou uma redução na podridão do pé do mamoeiro causada por $P$. palmivora.

No que diz respeito a variável área abaixo da curva de progresso da doença (AACPD), o tratamento com fungicida apresentou a menor AACPD $(120,55)$, diferindo estatisticamente apenas da testemunha e do tratamento AgroMos ${ }^{\circledR}$. Este por sua vez não foi eficiente na redução da doença, apresentando maior valor para AACPD $(2445,00)$ diferindo estatisticamente da testemunha (Figura 1).

Com exceção ao tratamento com AgroMos ${ }^{\circledR}$, todos os demais promoveram proteção nas plantas contra E. ampelina quando comparados a testemunha, com destaque para os tratamentos Fosfito de Potássio (87,67\%), Fungicida + Fosfito de Potássio (88,36\%) e Fungicida + Fosfito de Potássio $+\operatorname{AgroMos}^{\circledR}(81.66 \%)$ que propiciaram uma proteção semelhante a mesma promovida pelo fungicida $(89,94 \%)$, sendo estes, portanto, tratamentos alternativos eficiente no controle da antracnose da videira 'Isabel' em Natuba-PB.

$\mathrm{O}$ uso de fungicida proporcionou a maior proteção as plantas de videira 'Isabel', ao passo que, o tratamento com AgroMos ${ }^{\circledR}$ diferentemente dos demais, não promoveu proteção das plantas (Figura 1).

Tais resultados diferenciaram dos encontrados por Gomes et al., (10), onde as plantas tratadas somente com AgroMos ${ }^{\circledR}$ apresentaram valores com índice superior a $87 \%$ de proteção contra $P$. vitícola em videiras 'Isabel'.

Desta forma, a resistência sistêmica induzida em plantas pela utilização de elicitores de resistência, constituiu-se uma ferramenta importante no manejo das doenças da videira nas condições testadas, reduzindo os custos relacionados ao cultivo desta frutífera sem interferir de forma significativa na proteção contra a doença, quando comparados ao fungicida sintético, método de controle utilizado na região.

Em relação a pós-colheita destaca-se que os atributos físicos de qualidade dos frutos provavelmente foram influenciados pela aplicação de elicitores de resistência, em que os frutos de plantas tratadas com AgroMos ${ }^{\circledR}$ não diferiram da testemunha e apresentaram os menores valores do peso do fruto (99,50 e 91,88 g respectivamente). Apenas os frutos de plantas tratadas com fosfito de potássio diferiram estatisticamente da testemunha para as variáveis peso do fruto $(\mathrm{PF}) \mathrm{com}$ 144,62 g e em relação ao comprimento do cacho (CC) os frutos tratados com fosfito de potássio apresentam um maior comprimento $(11,50 \mathrm{~cm})$ em que se diferiram estaticamente dos tratamentos $\operatorname{AgroMos}^{\circledR}(9,49$ $\mathrm{cm})$ e Fungicida + Fosfito de Potássio $+\operatorname{AgroMos}^{\circledR}(9,03 \mathrm{~cm})$. Para a variável diâmetro de cacho (DC) os tratamentos se diferiram entre si, em que os frutos das plantas tratadas com fungicidas apresentaram um diâmetro maior $(6,22 \mathrm{~cm})$ que os tratados por AgroMos ${ }^{\circledR}$ e Fosfito de Potássio + $\operatorname{AgroMos}^{\circledR}(5,39$ e 5,12 cm respectivamente) e ambos não diferindo da testemunha conforme demonstrado na Tabela 2 .

Tabela 2. Peso do Cacho (PC), Comprimento do Cacho (CC), Diâmetro do Cacho (DC) e Rendimento de polpa (REND) dos frutos de uva Isabel (Vitis labrusca) 120 dias após a poda, tratados com elicitores de resistência no município de Natuba, PB.

\begin{tabular}{|c|c|c|c|c|}
\hline Tratamentos & PC (g) & $\mathrm{CC}(\mathrm{cm})$ & DC (cm) & $\operatorname{REND}(g)$ \\
\hline Fungicida (Metiram + Piraclostrobina) & $123,63 \mathrm{ab}$ & $10,86 \mathrm{ab}$ & $6,22 \mathrm{a}$ & 86,12 a \\
\hline Fosfito de Potássio & 144,62 a & $11,50 \mathrm{a}$ & $6,05 \mathrm{ab}$ & 77,12 a \\
\hline AgroMos $^{\circledR}$ & $99,50 \mathrm{~b}$ & $9,49 \mathrm{bc}$ & $5,39 \mathrm{bc}$ & 63,62 a \\
\hline 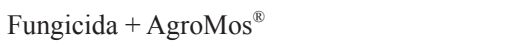 & $106,82 \mathrm{ab}$ & $10,37 \mathrm{abc}$ & $5,54 \mathrm{abc}$ & $67,12 \mathrm{a}$ \\
\hline Fosfito de Potássio + AgroMos ${ }^{\circledR}$ & $105,22 \mathrm{ab}$ & $9,83 \mathrm{abc}$ & $5,12 \mathrm{c}$ & $51,62 \mathrm{a}$ \\
\hline Fungicida + Fosfito de Potássio + AgroMos $^{\circledR}$ & $107,00 \mathrm{ab}$ & $9,03 \mathrm{c}$ & $5,87 \mathrm{abc}$ & $77,00 \mathrm{a}$ \\
\hline CV $(\%)$ & 15,02 & 7,55 & 7,82 & 12,06 \\
\hline
\end{tabular}

${ }^{1}$ Médias seguidas da mesma letra não diferem estatisticamente entre si pelo teste de Tukey até $5 \%$ de probabilidade. 

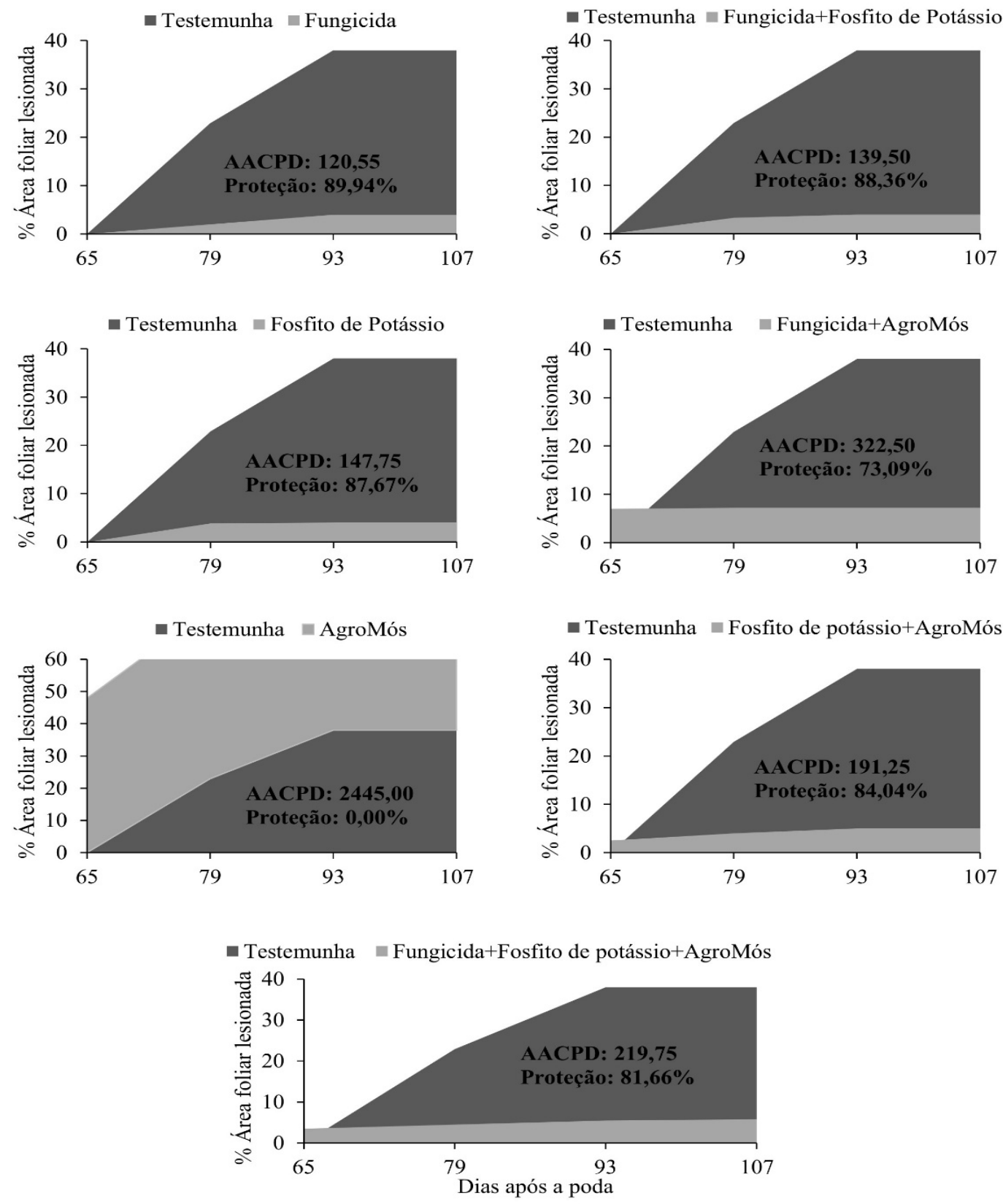

Figura 1. Evolução da doença a partir dos 65 dias após a poda e índice de proteção em relação à área abaixo da curva de progresso da doença (AACPD) em plantas de videira 'Isabel' submetidas a diferentes tratamentos com fungicidas e elicitores de resistência no município de Natuba-PB.

De acordo com Gomes et al., (9), o peso médio de cachos de uva 'Isabel' e o diâmetro dos cachos, foram significativamente influenciados pela utilização de elicitores aos 116 dias após a poda e plantas tratadas com fosfito de potássio e Rocksil ${ }^{\circledR}$ não diferiram de plantas tratadas com fungicidas para a variável peso dos cachos.

O rendimento de polpa do fruto não foi influenciado pelos tratamentos, assim, pode-se afirmar que o gasto energético desviado para indução da resistência nas plantas não interferiu em sua produção, quando comparado a plantas não pulverizadas (Tabela 2).

Pinto et al., (17), verificaram que as plantas tratadas com fosfito de potássio promovem nos frutos de uvas um maior acúmulo de massa, apresentando um aumento maior que $24 \%$ no volume final dos cachos quando comparado com a testemunha. Para Di Piero et al. (6), a quantidade de aplicações dos elicitores e as dosagem necessitam ser otimizadas para que não ocorram penalidades na produção.

O uso de elicitores alterou significativamente os teores de sólidos solúveis de frutos de uva 'Isabel' colhidos aos 120 dias após a poda, onde apenas os tratamentos Fungicida + Fosfito de potássio e Fungicida $+\operatorname{AgroMos}^{\circledR}$, não diferiram estatisticamente do tratamento com fungicida e com água. Os demais tratamentos elevaram os teores de sólidos solúveis (Tabela 3).

Segundo Chitarra \& Chitarra (4) os componentes da fração de sólidos solúveis, são os açúcares (frutose e glicose) e os ácidos tartárico e málico, fatores importantes do sabor da fruta, para a determinação do grau de maturação. Tais valores de teores de sólidos solúveis foram semelhantes aos indicados por Mascarenhas et al. (14), no qual obteve 
Tabela 3. Sólidos Solúveis (SS), pH, Acidez Titulável (AT) e Relação Sólidos Solúveis (SS) / Acidez Titulável (AT) de fruto de uva Isabel (Vitis labrusca) tratados com elicitores de resistência no município de Natuba, PB.

\begin{tabular}{|c|c|c|c|c|}
\hline Tratamentos & $\mathrm{pH}$ & SS (\%) & AT $(\%)$ & SS/AT \\
\hline Fungicida & $3,11 \mathrm{a}$ & $10,8 \mathrm{c}$ & $0,70 \mathrm{ab}$ & $15,54 \mathrm{a}$ \\
\hline Fosfito de Potássio & $3,10 \mathrm{a}$ & $11,8 \mathrm{bc}$ & $0,67 \mathrm{ab}$ & $17,76 \mathrm{a}$ \\
\hline $\operatorname{AgroMos}^{\circledR}$ & $3,04 \mathrm{a}$ & $16,5 \mathrm{a}$ & $0,88 \mathrm{ab}$ & $18,89 \mathrm{a}$ \\
\hline 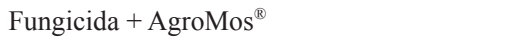 & $3,15 \mathrm{a}$ & $11,1 \mathrm{c}$ & $0,60 \mathrm{~b}$ & $18,64 \mathrm{a}$ \\
\hline Fosfito de Potássio + AgroMos $^{\circledR}$ & $3,06 \mathrm{a}$ & $15,1 \mathrm{ab}$ & $0,81 \mathrm{ab}$ & $18,70 \mathrm{a}$ \\
\hline Fungicida + Fosfito de Potássio + AgroMos $^{\circledR}$ & $2,96 \mathrm{a}$ & $14,9 \mathrm{ab}$ & $0,95 \mathrm{a}$ & $15,75 \mathrm{a}$ \\
\hline CV $(\%)$ & 2,72 & 10,99 & 15,71 & 26,80 \\
\hline
\end{tabular}

${ }^{1}$ Médias seguidas da mesma letra não diferem estatisticamente entre si pelo teste de Tukey até 5\% de probabilidade.

valores entre 13,63 e 15,97 de ${ }^{\circ}$ Brix para as cultivares Benitaka, Itália, Festival e Isabel comercializadas na Paraíba.

Para a variável AT (acidez titulável), apenas os tratamentos Fungicida + AgroMos $^{\circledR}$ e Fungicida + Fosfito de potássio + AgroMos $^{\circledR}$ diferiram estatisticamente entre si, mas não diferiram dos demais tratamentos, apresentando níveis mais baixos de ácido tartárico com $0,60 \%$ para a mistura com o fungicida e o AgroMos $^{\circledR}$ e níveis mais elevados, com uma média de $0,95 \%$ do mesmo ácido para a mistura com o fungicida, fosfito de potássio e $\operatorname{AgroMos}^{\circledR}$ (Tabela 3).

O desenvolvimento da acidez titulável apresenta-se associado ao fato dos principais ácidos das videiras (tartárico e málico) serem reduzidos pelas áreas foliar e pelos frutos ainda em estágio jovem, por isso, no princípio da maturação das bagas demonstram um alto teor de AT, e com o avanço da maturação, o consumo por energia eleva-se e para abastecer esta exigência sendo os ácidos gastos como fonte de energia na respiração celular ou concentração de carboidratos $(2 ; 22)$

Segundo Rizzon \& Sganzerla (19) valores médios de 4,35 g L-1 de ácido tartárico foi obtido em frutos de videira Isabel, apresentando teores médios superiores aos mostos das cultivares de $V$. vinifera do que nas cultivares da espécie $V$. labrusca quando foram comparados entre si.

No processo de maturação os principais ácidos da videira (tartárico e málico) são sintetizados através das folhas e das bagas ainda no estado inicial da sua formação, dessa maneira, nesta fase as bagas mostram-se com elevado teor de acidez titulável, por causa do aumento no consumo de energia e da diluição do mosto (13).

A aplicação dos tratamentos não influenciou na relação SS/AT, onde os tratamentos não se deferiram entre si, no qual apresentou valores entre 12,0 e 18,9 (Tabela 3 ).

No decorrer da maturação das bagas vão ocorrendo o acúmulo de açúcares, água e outras substâncias de reserva, e a redução da acidez, sendo ambas medidas necessárias para a definição da fase de maturidade de significância da máxima qualidade das bagas. A relação SS/AT corresponde a um índice de maturação demonstrado pelo equilíbrio entre o gosto adocicado e o ácido presente no suco da uva (18).

Com relação ao $\mathrm{pH}$, não houve influência dos tratamentos nesta variável não apresentando diferença significativa entre os tratamentos, em que o maior valor encontrado foi de 3,15 (Tabela 3), enquadrando-se nos valores médios que são indicados para esta variedade (8).

Pode-se inferir como conclusão do trabalho que o fosfito de potássio aplicado sozinho ou intercalado com fungicida em videiras 'Isabel', no município de Natuba, PB, proporcionou menor severidade nas plantas contra E. ampelina.

O comprimento e peso dos cachos de uva foram influenciados positivamente com a aplicação de fosfito de potássio e os elicitores de resistência (Fosfito de potássio e AgroMos ${ }^{\circledR}$ ) aplicados isoladamente ou em conjunto, não interferiram no rendimento de polpa.

\section{REFERÊNCIAS}

1. Aoac - Association of official analytical chemists. Official methods of analysis of the association of official analytical chemists. 12. ed. Washington: DC, 1984. $1094 \mathrm{p}$

2. Blouin, J.; Guimberteau, G. Maduracion y madurez de la uva. Madrid: Ediciones Mundi-Prensa, $2004.151 \mathrm{p}$.

3. Carmona, M.; Sautua, F. Os fosfitos no manejo de doenças nas culturas extensivas. Revista Plantio Direto, Passo Fundo, v. 126, n. 6, p.19-22, 2011.

4. Chitarra, M. I. F.; Chitarra, A. B. Pós-colheita de frutas e hortaliças: fisiologia e manuseio. 2. ed. Lavras: UFLA, 2005. 783p.

5. Dias-Arieira, C.R.; Ferreira, L.R.; Arieira, J.O. Atividade do óleo de Eucalyptus citriodora e Azadirachta indica no controle de Colletotrichum acutatum em morangueiro. Summa Phytopathologica, Botucatu, v.36, n. 3, p. 228-232, 2010.

6. Di Piero, R. M.; Kuhn, O. J.; Pascholati, S. F. Indução de resistência e a produtividade das culturas. In: Cavalcanti, L. S.; Di Piero, R. M.; Cia, P.; Pascholati, S. F.; Resende, M. L. V.; Romeiro, R. S. Indução de resistência em plantas a patógenos. Piracicaba: FEALQ, 2005, p. 239-255.

7. Dianese, A. C.; Blum, L. E. B.; Dutra, J. B.; Lopes, L. F. Aplicação de fosfito de potássio, cálcio ou magnésio para a redução da podridão-do-pé do mamoeiro em casa de vegetação. Ciência Rural, Santa Maria, v.39, n. 8, p. 2309-2314, 2009.

8. Embrapa. Empresa Brasileira de Pesquisa Agropecuária. Embrapa Uva e Vinho. Sistema de produção. Santa Cruz do Sul: Gazeta, n. 9, p 17-18, 2006.

9. Gomes, E. C. S.; Perez, J. O.; Barbosa, J. Resistência induzida como componente do manejo de doenças da videira. Engenharia Ambiental: Pesquisa e Tecnologia, Espírito Santo do Pinhal, v. 6, n. 2, p. 114-120, 2009.

10. Gomes, E. C. S.; Perez, J. O.; Barbosa, J.; Nascimento, E. F.; Aguiar, I. F. Efeito de indutores de resistência na proteção de uva "Itália" e uva de vinho "Cabernet Sauvignon" contra o oídio e o míldio no Vale do São Francisco. In: Congresso de Pesquisa e Inovação da Rede Norte Nordeste de Educação Tecnológica, 2., 2007, João Pessoa. Anais. João Pessoa: Rede NET, 2007. p 1-9.

11. Ibge. Instituto Brasileiro de Geografia e Estatística. Banco de dados agregados. Rio de Janeiro, 2016. Disponível em: $<\mathrm{http}$ ://www.sidra.ibge.gov. br. >. Acesso em: 27 mar. 2017.

12. Kramer, A. Fruits and Vegetables. In: __ e Twigg, B. A. Quality Control 
for the Food Industry. Connecticut: Avi Publishing Company, 1973. v. 2, p. 157-227.

13. Manfroi, L.; Miele, L.; Rizzon, L. A.; Barradas, C. I. N.; Souza, P. V. D. Evolução da maturação da uva 'Cabernet Franc' conduzida no sistema lira aberta. Ciência Agrotecnica, Lavras, v. 28, n. 2, p. 306-313, 2004.

14. Mascarenhas, R. J.; Silva, S. M.; Lopes, J. D.; Lima, M. A. L. Avaliação sensorial de uvas de mesa produzidas no Vale do São Francisco e comercializadas em João Pessoa-PB. Revista Brasileira de Fruticultura, Jaboticabal, v. 32 , n. 4, p. $993-1000,2010$

15. Mello, L. M. R. Atuação do Brasil no mercado vitivinícola mundial: panorama 2012. Bento Gonçalves, RS. Comunicado Técnico 138 Embrapa Uva e Vinho, 2013. Disponível em: < http://www.cnpuv.embrapa.br/publica/ comunicado/cot138.pdf $>$. Acesso em: 8 ago. 2013.

16. Oliveira, A. F. Produtividade da soja e severidade de ferrugem asiática (Phakopsora pachyrhizi) influenciadas pela aplicação foliar com fontes de potássio e doses de tebuconazole.2007. 51 f. Dissertação (Mestrado em Agronomia) - Universidade Federal de Uberlândia, Uberlândia.

17. Pinto, K. M. S.; Nascimento, L. C.; Oliveira, A. K.; Leite, R. P.; Silva, J. P. Resistência induzida em frutos de videira 'Isabel' (Vitis Labrusca) e seus efeitos sobre a qualidade pós-colheita. Revista Brasileira de Fruticultura, Jaboticabal, v. 35, n. 1, p. 210-217, 2013.

18. Rizzon, L. A.; Link, M. Composição do suco de uva caseiro de diferentes cultivares. Ciência Rural, Santa Maria, v. 26, n. 2, p. 689-692, 2006.

19. Rizzon, L. A.; Sganzerla, A. Ácidos tartárico e málico no mosto de uva Bento Gonçalves-RS. Ciência Rural, Santa Maria, v. 37, n. 3, p. 911-914, 2007.

20. Silva, F. A. S.; Azevedo, C. A. V. Versão do programa computacional Assistat para o sistema operacional Windows. Revista Brasileira de Produtos Agroindustriais, Campina Grande, v. 4, n. 01, p. 71-78, 2002.

21. Silva, O. C.; Santos, H. A. A.; Dalla Pria, M.; May-De Mio, L. L. Potassium phosphite for control of downy mildew of soybean. Crop Protection, Guildford, v. 30, n. 6, p. 598-604, 2011.

22. Taiz, L.; Zeiger, E. Fisiologia vegetal. Tradução Santarém, E. R.; Mariath, J. E. A.; Astarita, L. V.; Dillenburg, L. R.; Rosa, L. M. G.; Oliveira, P. L. 3. ed. Porto Alegre: Artmed, 2006. 722 p.

23. Tessmann, D. J.; Vida, J. B.; Genta, W.; Kishino, A. Y. Doenças e seu manejo. In: Kishino, A. S.; Carvalho, S. L. C.; Roberto, S. R. Viticultura Tropical: O sistema de produção do Paraná. Londrina: IAPAR, 2007, p. 255-304. 